\title{
Regioselectively Modified Stereoregular Polysaccharides IX. A Synthetic Polysaccharide Having One Hydroxyl Group in Its Repeating Unit, 2,4-Dideoxy- $(1 \rightarrow 6)-\alpha$-D-threo-hexopyranan
}

\author{
Kazukiyo KobaYASHI, Hiroshi Sumitomo, Haruo ICHIKAWA, \\ and Hiroaki SUGIURA \\ Faculty of Agriculture, Nagoya University, \\ Chikusa, Nagoya 464, Japan
}

(Received June 13, 1986)

\begin{abstract}
A new synthetic linear dextran having one hydroxyl group in position 3 of each

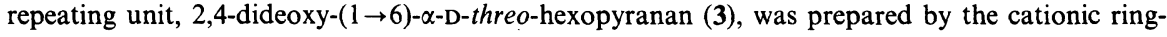
opening polymerization of 1,6-anhydro-3-O-benzyl-2,4-dideoxy- $\beta$-D-threo-hexopyranose (1), followed by debenzylation. The 1,6-anhydro dideoxy compound 1 was obtained from microcrystalline cellulose via four step reactions. The polymerization of 1 was carried out using phosphorus pentafluoride and boron trifluoride diethyl etherate at temperatures ranging from -90 to $0^{\circ} \mathrm{C}$. The stereoregular polymer with $\alpha$-anomeric configuration, 3-O-benzyl-2,4-dideoxy-(1 $\rightarrow 6)$ - $\alpha$-D-threohexopyranan (2), was obtained at lower temperature in high yield. Disordering of the stereoregularity depending upon polymerization conditions was estimated by the ${ }^{13} \mathrm{C}$ NMR spectrum and specific optical rotation. The high reactivity of 1 in polymerization, copolymerization, and acidcatalyzed solvolysis is discussed on the basis of the electronic and steric effects for the deoxygenated structure of $\mathbf{1}$. Debenzylation of $\mathbf{2}$ with sodium metal in liquid ammonia afforded a white powdery polymer identified as 3 by the ${ }^{13} \mathrm{C}$ NMR spectroscopy.
\end{abstract}

KEY WORDS Anhydro Sugar / Ring-Opening Polymerization / Synthetic Polysaccharide / Deoxygenated Polysaccharide /

Polysaccharide synthesis via ring-opening polymerization of anhydro sugar derivatives is a useful method for preparing polysaccharides with well-defined structure, ${ }^{1,2}$ and an important target of this method is to synthesize regioselectively modified polysaccharides. For this purpose, we previously adopted 1,6-anhydro-2,4-di- $O$-benzyl- $\beta$-D-glucopyranose as a precursor. ${ }^{3-9}$ The free hydroxyl group in position 3 was modified by acetylation, ${ }^{3}$ alkylation, ${ }^{4,5,7,8}$ deoxygenation, ${ }^{6}$ and oxidation, ${ }^{9}$ and the resulting compounds were polymerized and then deprotected to give desired polysaccharides.

1,6-Anhydro-2,4-dideoxy- $\beta$-D-threo-hexopyranose is of interest as another precursor because it can be prepared simply and quickly ${ }^{10}$ and has a potentially reactive skeleton of deoxygenated anhydro sugars. In this paper, polymerization of its benzylation product 1,6-anhydro-3-O-benzyl-2,4-dideoxy$\beta$-D-threo-hexopyranose (1) was attempted and 2,4 -dideoxy- $(1 \rightarrow 6)$ - $\alpha$-D-threo-hexopyranan (3) synthesized according to Scheme I. Compound $\mathbf{1}$ is an optically active bicyclic acetal with one benzyloxy substituent in the C-3 axial position. There have been several reports on polymerization of benzylated monodeoxy-6,11-14 and dideoxy ${ }^{15,16}$ 1,6anhydro sugars, which include the optically active- $^{6,11,14}$ and racemic $^{12,13,15,16}$ ones of carbohydrate- ${ }^{6,11}$ and noncarbohydrate ${ }^{12-16}$ origin. Discussion on the polymerization reactivity of $\mathbf{1}$ is made in terms of the position 


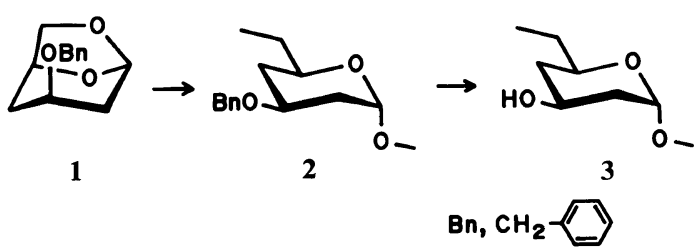

Scheme I. Synthesis of 2,4-dideoxy-(1 $\rightarrow 6)-\alpha$-D-threohexopyranan.

and orientation of the benzyloxy substituent.

\section{EXPERIMENTAL}

\section{Monomer Synthesis}

1,6-Anhydro-2, 3, 4-tri- $O$-benzyl- $\beta$-D-glucopyranose $^{1,4}$ and 6,8-dioxabicyclo[3.2.1]octane ${ }^{17-19}$ were synthesized according to the method previously described. 1,6-Anhydro3- $O$-benzyl-2, 4-dideoxy- $\beta$-D-threo-hexopyranose (1) was synthesized via four step reactions from microcrystalline cellulose as shown in Scheme II. Microcrystalline cellulose kindly supplied by Asahi Chemicals Co. was pyrolyzed under reduced pressure $(1 \mathrm{~mm}$ $\mathrm{Hg}$ ) to give 1,6-anhydro- $\beta$-D-glucopyranose (yield, $37 \%$ ). 1,6-Anhydro-2,4-di- $O$ - $p$-toluenesulfonyl- $\beta$-D-glucopyranose was synthesized as described ${ }^{20}$ (yield, $89 \%$ ).

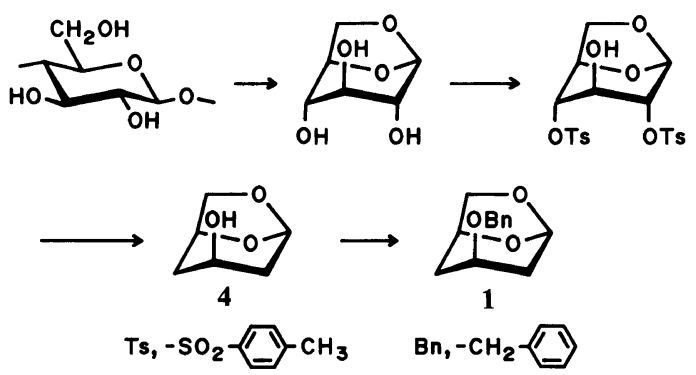

Scheme II. Synthesis of 1,6-anhydro-3-O-benzyl-2,4dideoxy- $\beta$-D-threo-hexopyranose.

\section{1,6-Anhydro-2,4-dideoxy- $\beta$-D-threo-hexopy- ranose $(4)^{10}$}

The monomer precursor 4 was synthesized according to the method described by Kelly et al. ${ }^{10}$ 1,6-Anhydro-2,4-di-O- $p$-toluenesulfonyl- $\beta$-D-glucopyranose (6.5 g) was dissolved in $100 \mathrm{ml}$ of dry tetrahydrofuran (THF), and cooled below $0^{\circ} \mathrm{C}$ in an atmosphere of dry nitrogen. Lithium triethylborohydride solution in THF $(0.28 \mathrm{M}, 100 \mathrm{ml})$ was added dropwise, and the solution was stirred at room temperature for $24 \mathrm{~h}$. After the reaction solution was cooled below $0^{\circ} \mathrm{C}, 15 \mathrm{ml}$ of deionized water, $100 \mathrm{ml}$ of $3 \mathrm{M}$ aqueous sodium hydroxide solution, and $80 \mathrm{ml}$ of $30 \%$ hydrogen peroxide were successively added. The mixture was extracted with dichloromethane, and the organic layer was concentrated to give a colorless viscous liquid which included 4 and an isomer 1,6-anhydro-3,4-dideoxy- $\beta$-Dthreo-hexopyranose. The crude product was purified by silica gel column chromatography (eluent, ethyl acetate/triethylamine 20:1 $\mathrm{v} / \mathrm{v})$ and 4 was isolated in a yield of $1.3 \mathrm{~g}$ $(73 \%)$.

\section{1,6-Anhydro-3-O-benzyl-2,4-dideoxy- $\beta$ - $D$ - threo-hexopyranose $(\mathbf{1})^{21}$}

To the solution of $4(2.0 \mathrm{~g})$ in THF $(25 \mathrm{ml})$ were added $0.64 \mathrm{~g}$ of sodium hydride, $0.054 \mathrm{~g}$ of tetrabutylammonium iodide, and $1.8 \mathrm{ml}$ of benzyl bromide. The solution was stirred at room temperature for $1.5 \mathrm{~h}$, and then another portion of sodium hydride $(0.64 \mathrm{~g})$, tetrabutylammonium iodide $(0.054 \mathrm{~g})$, and benzyl bromide $(1.8 \mathrm{ml})$ was added. The solution was stirred at room temperature for another $3 \mathrm{~h}$ and at $50^{\circ} \mathrm{C}$ for $1 \mathrm{~h}$. The reaction was quenched by the addition of excess amount of water and the product was extracted with chloroform and purified by silica gel column chromatography to give a viscous liquid $(2.73 \mathrm{~g}, 82 \%)$. Anal. Calcd for $\mathrm{C}_{13} \mathrm{H}_{16} \mathrm{O}_{3}: \mathrm{C}$, $70.89 \%$;, $7.32 \%$. Found: C, 70.89\% $\mathrm{H}$, $7.38 \% \cdot[\alpha]_{\mathrm{D}}^{25}-58.0^{\circ}(c=1$, in chloroform $) .{ }^{13} \mathrm{C}$ NMR $\left(\mathrm{CDCl}_{3}\right)$ 138.4, phenyl (ipso); 128.1, phenyl (meta); 127.1, phenyl (ortho and para); 100.0, C-1; 71.5, C-3; 70.3, $\mathrm{CH}_{2}$ (benzyl); 69.6, C-5; 67.6, C-6; 35.2, C-2; 33.6, C-4. 


\section{Polymerization}

Polymerization was carried out by high vacuum technique. ${ }^{1,3-9}$ Monomer 1 was dissolved in dichloromethane and dried over calcium hydride. The solution was transferred through a glass filter into a polymerization tube and the solvent was distilled off in vacuum until the prescribed monomer concentration was attained. The initiator break-seal was broken and the initiator was transferred into the polymerization tube previously cooled in a liquid nitrogen bath. Phosphorus pentafluoride was generated by thermal degradation of the precursor $p$-chlorobenzenediazonium hexafluorophosphate. Boron trifluoride diethyl etherate was used as a dichloromethane solution prepared in a breaksealed ampule under high vacuum. The polymerization was carried out in a thermostatcontrolled refrigerator with occasional shaking. A small amount of pyridine was added to terminate the polymerization and the mixture was poured into a large volume of methanol. The product was purified by repeating the reprecipitation from its chloroform solution into methanol. ${ }^{13} \mathrm{C}$ NMR $\left(\mathrm{CDCl}_{3}\right)$ of the stereoregular polymer 2: 138.4, phenyl (ipso); 128.2, phenyl (meta); 127.3, phenyl (ortho and para); 97.7, C-1; 70.9, C-3; 69.9, $\mathrm{CH}_{2}$ (benzyl); 69.0, C-6; 66.8, C-5; 36.2, C-2; 34.3, C-4.

\section{Debenzylation}

Polymer $(0.3 \mathrm{~g})$ was dissolved or dispersed in a mixture of toluene $(30 \mathrm{ml})$ and 1,2-dimethoxyethane $(15 \mathrm{ml})$ and was added to $50 \mathrm{ml}$ of liquid ammonia with stirring at $-33^{\circ} \mathrm{C}$. Small pieces of freshly cut sodium metal were added to the solution until the dark blue of the solution persisted. Ammonium chloride and excess water were added, ammonia was evaporated, and the residue was washed with dichloromethane to remove any unreacted polymer. A deblocked polymer was obtained from both the precipitate and aqueous solution. The precipitate was separated by centrifugation and dissolved in dimethyl sulfoxide
$\left(\mathrm{Me}_{2} \mathrm{SO}\right)$. Insoluble impurities were removed by filtration, the filtrate was poured into a large volume of methanol, and the resulting white powdery polymer was dried in vacuo. The aqueous solution was dialyzed in water for 2 days, concentrated, and freeze-dried to give a white powdery polymer.

\section{Characterization}

${ }^{1} \mathrm{H}$ and ${ }^{13} \mathrm{C}$ NMR spectra were recorded on a Japan Electron Optics Laboratory JNMFX-200 Fourier transform NMR spectrometer operating at 200 and $50 \mathrm{MHz}$, respectively. Chloroform- $d$ and $\mathrm{Me}_{2} \mathrm{SO}-d_{6}$ were used as solvents and tetramethylsilane as the internal standard. Optical rotations were determined at $25^{\circ} \mathrm{C}$ in a Japan Spectroscopic Co. DIP181 digital polarimeter using a water-jacketed $1-\mathrm{dm}$ cell. Melting points of benzylated polysaccharides were determined by a Perkin Elmer DSC-2 differential scanning calorimeter at a heating rate of $10 \mathrm{deg} \mathrm{min}^{-1}$. The number average molecular weights of benzylated polysaccharides were estimated by gel permeation chromatography on a Hitachi 634A high performance liquid chromatograph with a Shodex GPCA- $80 \mathrm{M}$ column $(8 \mathrm{~mm} \phi$ $\times 1000 \mathrm{~mm}$; polystyrene standards; solvent, chloroform).

\section{RESULTS AND DISCUSSION}

\section{Polymerization of 1,6-Anhydro-3-O-benzyl-} 2,4-dideoxy- $\beta$-D-threo-hexopyranose (1)

The results of the polymerization of 1 are summarized in Table I. The polymerization was carried out in dichloromethane at different temperatures between -90 and $0^{\circ} \mathrm{C}$. Both phosphorus pentafluoride $\left(\mathrm{PF}_{5}\right)$ and boron trifluoride diethyl etherate $\left(\mathrm{BF}_{3} \mathrm{OEt}_{2}\right)$ were effective initiators and the polymerization proceeded promptly. A higher polymerization rate was attained by phosphorus pentafluoride and the highest polymer yield was $97 \%$ (exptl. no. I-44).

A white powdery polymer was obtained. 
Table I. Polymerization of 1,6-anhydro-3-O-benzyl-2,4-dideoxy- $\beta$-D-threo-hexopyranose ${ }^{\mathrm{a}}$

\begin{tabular}{|c|c|c|c|c|c|c|c|c|c|c|c|c|}
\hline \multirow{2}{*}{$\begin{array}{c}\text { Exptl. } \\
\text { No. }\end{array}$} & \multicolumn{2}{|c|}{ Monomer } & \multicolumn{2}{|c|}{ Initiator } & \multirow{2}{*}{$\frac{\text { Temp }}{{ }^{\circ} \mathrm{C}}$} & \multirow{2}{*}{$\frac{\text { Time }}{\min }$} & \multicolumn{2}{|c|}{ Yield $\beta$-Form ${ }^{\mathrm{b}}$} & \multirow{2}{*}{$\frac{[\alpha]_{D}^{25 c}}{\operatorname{deg}}$} & \multirow{2}{*}{$\frac{\mathrm{mp}^{\mathrm{d}}}{{ }^{\circ} \mathrm{C}}$} & \multirow{2}{*}{$\begin{array}{c}\bar{M}_{n}^{\mathrm{e}} \\
\times 10^{-4}\end{array}$} & \multirow{2}{*}{$\bar{M}_{w} / \bar{M}_{n}^{\mathrm{e}}$} \\
\hline & \multicolumn{2}{|c|}{$\mathrm{mmol} \mathrm{moll}^{-1}$} & \multicolumn{2}{|c|}{$\mathrm{mol} \%$ to monomer } & & & $\%$ & $\%$ & & & & \\
\hline $\mathrm{I}-40$ & 2.0 & 1.0 & $\mathrm{PF}_{5}$ & 2.5 & -90 & 120 & 66 & $\sim 0^{1}$ & +127.0 & $163-177$ & 1.0 & 3.3 \\
\hline $\mathrm{I}-29$ & 2.0 & 1.0 & $\mathrm{PF}_{5}$ & 5.0 & -90 & 60 & 82 & $\sim 0$ & +133.1 & $165-178$ & 1.6 & 4.7 \\
\hline $\mathrm{I}-38$ & 2.0 & 1.0 & $\mathrm{PF}_{5}$ & 2.5 & -78 & 30 & 90 & $\sim 0^{1}$ & +126.9 & $157-175$ & 1.5 & 4.4 \\
\hline $\mathrm{I}-28$ & 2.0 & 1.0 & $\mathrm{PF}_{5}$ & 5.0 & -78 & 30 & 68 & $\sim 0^{1}$ & +127.4 & $159-174$ & 1.5 & 5.0 \\
\hline I-41 & 2.0 & 1.0 & $\mathrm{PF}_{5}$ & 0.5 & -60 & 120 & 14 & $\sim 0$ & +137.7 & $167-178$ & 1.6 & 4.7 \\
\hline $\mathrm{I}-42$ & 2.0 & 1.0 & $\mathrm{PF}_{5}$ & 1.0 & -60 & 120 & 61 & $\sim 0$ & +131.6 & $164-178$ & 1.4 & 3.8 \\
\hline $\mathrm{I}-44$ & 2.0 & 1.0 & $\mathrm{PF}_{5}$ & 2.5 & -60 & 30 & $97^{\mathrm{f}, \mathrm{g}}$ & $\sim 0$ & +134.1 & $162-176$ & 1.5 & 3.2 \\
\hline $\mathrm{I}-30$ & 2.0 & 1.0 & $\mathrm{PF}_{5}$ & 5.0 & -60 & 15 & $60^{\mathrm{h}}$ & $\sim 0^{1}$ & +127.1 & $153-173$ & 1.2 & 2.7 \\
\hline $\mathrm{I}-46$ & 3.4 & 1.4 & $\mathrm{PF}_{5}$ & 5.8 & -60 & 3 & 81 & $\sim 0^{1}$ & +128.8 & $149-167$ & 1.2 & 3.7 \\
\hline \multirow[t]{2}{*}{ S-1 } & 3.4 & 1.4 & $\mathrm{PF}_{5}$ & 5.8 & -60 & 120 & $62^{\mathrm{i}}$ & 4 & $+113.5^{\mathrm{i}}$ & $136-149^{i}$ & $1.2^{\mathrm{i}}$ & $1.8^{\mathrm{i}}$ \\
\hline & & & & & & & $25^{\mathbf{j , k}}$ & 13 & $+108.1^{j}$ & $135-145^{\mathrm{j}}$ & $0.54^{\mathrm{j}}$ & $1.9^{\mathrm{j}}$ \\
\hline I-37 & 2.0 & 1.0 & $\mathrm{PF}_{5}$ & 2.5 & -40 & 10 & 77 & 7 & +117.4 & $141-155$ & 1.2 & 2.3 \\
\hline I-39 & 2.0 & 1.0 & $\mathrm{BF}_{3} \mathrm{OEt}_{2}$ & 2.5 & -60 & 1 day & 17 & $\sim 0$ & +131.7 & $171-182$ & 0.99 & 3.6 \\
\hline $\mathrm{I}-31$ & 4.0 & 1.3 & $\mathrm{BF}_{3} \mathrm{OEt}_{2}$ & 3.4 & -60 & 360 & 87 & $\sim 0^{1}$ & +127.5 & $156-171$ & 1.5 & 3.1 \\
\hline $\mathrm{I}-43$ & 2.0 & 1.0 & $\mathrm{BF}_{3} \mathrm{OEt}_{2}$ & 2.5 & -40 & 120 & 82 & $\sim 0$ & +135.8 & $168-181$ & 1.2 & 2.8 \\
\hline $\mathrm{I}-47$ & 2.0 & 1.0 & $\mathrm{BF}_{3} \mathrm{OEt}_{2}$ & 2.5 & 0 & 20 & 46 & 6 & +113.2 & $136-154$ & 0.53 & 1.6 \\
\hline
\end{tabular}

a Solvent, dichloromethane.

b Determined by ${ }^{13} \mathrm{C}$ NMR spectroscopy.

c In chloroform; $c, 1.0 \mathrm{~g} / 100 \mathrm{ml}$.

d Determined by DSC.

e Determined by GPC using polystyrene standards in chloroform.

f Anal. Calcd for $\left(\mathrm{C}_{13} \mathrm{H}_{16} \mathrm{O}_{3}\right)_{n}$ : C, $70.89 \% ; \mathrm{H}, 7.32 \%$. Found: C, $70.88 \% ; \mathrm{H}, 7.36 \%$.

g Extraction with benzene gave a benzene-soluble fraction less than $1 \%$.

h Extraction with benzene gave a $13 \%$ benzene-soluble fraction $\left(\bar{M}_{n}, 0.63 \times 10^{4}\right)$ and a $87 \%$ benzene-insoluble fraction $\left(\bar{M}_{n}, 2.1 \times 10^{4}\right)$.

i Benzene-insoluble fraction.

j Benzene-soluble fraction.

k Anal. Calcd for $\left(\mathrm{C}_{13} \mathrm{H}_{16} \mathrm{O}_{3}\right)_{n}$ : C, $70.89 \% ; \mathrm{H}, 7.32 \%$. Found: C, $70.60 \% ; \mathrm{H}, 7.35 \%$.

${ }^{1}$ It is possible that the polymer contains less than $3 \% \beta$-form as judged by the $[\alpha]_{D}^{25}$ data.

It was soluble in chloroform and dichloromethane, partially soluble in benzene and toluene, and insoluble in other common organic solvents. The specific rotation was positive and high. The melting point determined by differential scanning calorimeter was higher than those of other analogous benzylated polysaccharides. $^{5-8}$ GPC showed that the number average molecular weight was in the range of 5,300 to 16,000 , which corresponded to DP of 24 to 73 , and the molecular weight distribution was wide compared to those of the analogs. The elemental analytical data as described in the footnote of Table I were satisfactory.

The typical ${ }^{13} \mathrm{C}$ NMR spectrum of the polymers is presented in Figure 1. There appeared only a set of ten sharp signals assignable to the stereoregular 3-O-benzyl-2,4-di-

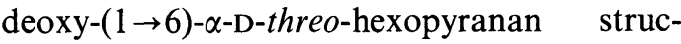
tural unit (2). The chemical shifts and their assignments are discribed in Exprimental Section. Compared with the chemical shifts of a completely deoxygenated skeletal polymer 2,3,4-trideoxy-( $(\rightarrow 6)-\alpha$-L-glycero-hexopyranan, ${ }^{18}$ the benzyloxy substitution in place of the equatorial hydrogen atom in position 3 of each pyranose unit caused a $53 \mathrm{ppm}$ downfield shift for the $\mathrm{C}-3$ resonance and a $6.9 \mathrm{ppm}$ downfield shift for each of the adjacent C-2 and C-4. No resonance due to the $\beta$-configurational unit was observed. 


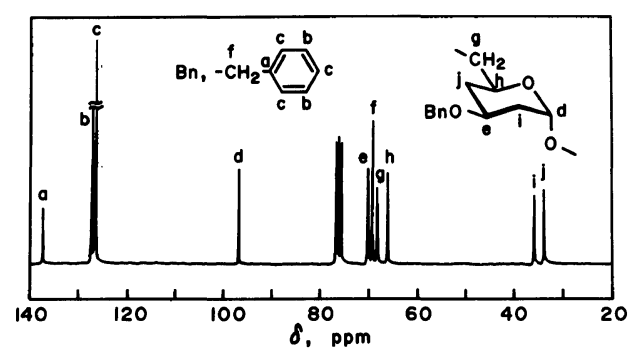

Figure 1. $50 \mathrm{MHz}^{13} \mathrm{C} \mathrm{NMR}$ spectrum of stereoregular 3-O-benzyl-2,4-dideoxy- $(1 \rightarrow 6)$ - $\alpha$-D-threo-hexopyranan. Solv., $\mathrm{CDCl}_{3}$; concentration, $2.5 \% ; \mathrm{Me}_{4} \mathrm{Si}$ standard.

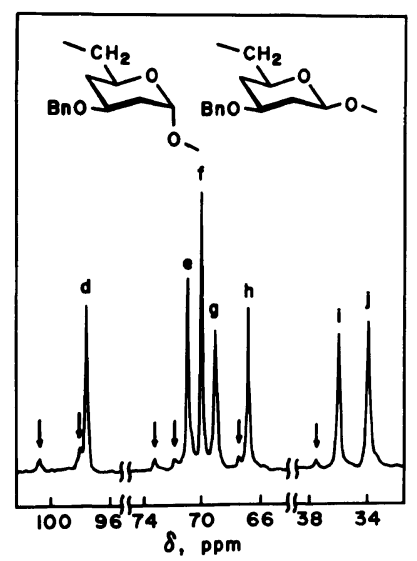

Figure 2. $50 \mathrm{MHz}$ expanded ${ }^{13} \mathrm{C}$ NMR spectrum of the stereoirregular polymer. Solv., $\mathrm{CDCl}_{3}$; concentration, $6 \% ; \mathrm{Me}_{4} \mathrm{Si}$ standard.

Figure 2 shows an expanded ${ }^{13} \mathrm{C}$ NMR spectrum of the other polymers (exptl. no. S-1, I-37, and I-47) suggesting the presence of a small portion of the $\beta$-structural unit along the polymer chain. In addition to the large resonances due to the stereoregular $\alpha$-configurational unit, six small resonances whose intensity was independent on the molecular weight of the polymer were observed as indicated by arrows. Three signals with different intensities were detected in the $\mathrm{C}-1$ anomer region: an isolated downfield small signal at $100.8 \mathrm{ppm}$ assignable to $\beta-\mathrm{C}-1$ and a large peak (d) at $97.7 \mathrm{ppm}$ with a shoulder at $98.1 \mathrm{ppm}$ assignable to $\alpha-\mathrm{C}-1$. It is reasonable to assume that the splitting of the $\alpha-C-1$ resonance is due to the dyad sequence and the shoulder to the $\alpha$ - structural unit adjacent to the $\beta$-structural one. ${ }^{18}$ The peak ratio of the $\alpha$ - and $\beta$-anomeric signals gave an estimate of $\beta$-anomer content as listed in Table I. The other arrowed signals were also caused by the presence of the $\beta$ anomeric unit although no detailed assignment was made.

The specific optical rotation of the polymers, a measure of the stereoregularity, varied depending on the polymerization conditions. Little correlation was detected between the rotations and molecular weights of the polymers, but the polymer with a lower rotation had a lower melting point as depicted in Figure 3 . The polymer with a lower rotation also showed a hight solubility in benzene. As examples, the content of the benzene-soluble fraction was less than $1 \%$ for $\mathrm{I}-44\left([\alpha]_{\mathrm{D}}^{25}=\right.$ $\left.+134.1^{\circ}\right), 13 \%$ for $\mathrm{I}-30\left([\alpha]_{\mathrm{D}}^{25}=+127.1^{\circ}\right)$, and $29 \%$ for S-1. It was found that the polymers having lower rotation $\left(+108^{\circ}-+116^{\circ}\right)$ contained the $\beta$-anomeric structural unit $(4-13 \%)$ as estimated from the ${ }^{13} \mathrm{C}$ NMR spectroscopy. We assume that the polymers of the higher rotation $\left([\alpha]_{D}^{25}>130^{\circ}\right)$ have the complete $\alpha$-anomeric structure. However, it is possible that the polymers of the intermediate rotation $\left(+130^{\circ}>[\alpha]_{\mathrm{D}}^{25}>125^{\circ}\right)$ contain small amounts of the $\beta$-anomeric unit (less than $3 \%$ ) although the $\beta$-anomeric unit could not be detected owing to the limited sensitivity of the ${ }^{13} \mathrm{C}$ NMR spectroscopy.

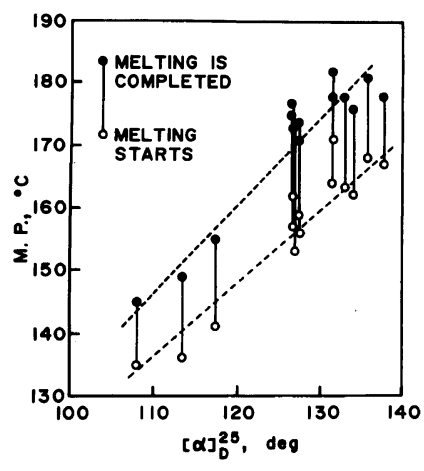

Figure 3. Relationship between specific optical rotation and melting point of the polymer 2 . 


\section{K. Kobayashi et al.}

Complete $\alpha$-anomeric stereoregular poly$\operatorname{mers}\left([\alpha]_{\mathrm{D}}^{25}>+130^{\circ}\right)$ were obtained when 1 was polymerized at lower temperature for shorter time. On the other hand, the stereoregularity along the polymer chain was lowered at higher polymerization temperature. Even at a low temperature, the stereoregularity was disordered when the polymerization was carried out for longer time. For an example, compare the $\beta$-anomeric content and the specific rotation between the polymers I-46 and $\mathrm{S}-1$. The stereoregularity also tended to be lowered when $\mathrm{PF}_{5}$ rather than $\mathrm{BF}_{3} \mathrm{OEt}_{2}$ was used (compare I-37 and I-43; S-1 and I-31) and the amount of $\mathrm{PF}_{5}$ was increased (compare I-44 and I-30).

Reactivity of 1,6-Anhydro-3-O-benzyl-2,4-dideoxy- $\beta$-D-threo-hexopyranose (1) in polymerization, copolymerization, and solvolysis

Copolymerization (Table II) and acidcatalyzed solvolysis were attempted to obtain information on the reactivity of $\mathbf{1}$. The copolymerization between 1 and 1,6-anhydro2,3,4-tri- $O$-benzyl- $\beta$-D-glucopyranose (5) was carried out in a $0.5: 0.5$ molar feed with use of $\mathrm{PF}_{5}$ initiator. The resulting polymer was found to be composed almost entirely of the structural unit 1 . The copolymerization between 1 and racemic 6,8-dioxabicyclo[3.2.1]octane (6) was carried out with the $\mathrm{BF}_{3} \mathrm{OEt}_{2}$ initiator and terminated at a low conversion. The $\alpha$-anomeric C-1 resonance of the unit 1 in the ${ }^{13} \mathrm{C}$ NMR spectrum was split into two peaks due to the dyad copolymer sequence, which is evidence of copolymerization. In its
${ }^{1} \mathrm{H}$ NMR spectrum, the anomeric protons of the structural units of $\mathbf{1}$ and $\mathbf{6}$ were observed at 5.05 and $4.88 \mathrm{ppm}$, respectively, whose area ratio was $0.36: 0.64$.

Acid-catalyzed solvolysis of 1 was carried out at an ambient temperature in a mixed solvent of acetone- $d_{6}$ and deuterium oxide (volume ratio $3: 1$ ) in the presence of dichloroacetic acid as catalyst. ${ }^{22,23}$ The reaction was followed by the disappearance of the $\beta$-C-1 carbon signal, and 1 was hydrolyzed at a rate of $1.3 \times 10^{-6} \mathrm{~s}^{-1}$. Under similar conditions, 6 was hydrolyzed more rapidly $\left(5.0 \times 10^{-6}\right.$ $\left.\mathrm{s}^{-1}\right),{ }^{23}$ but several related compounds including 5 and some deoxy 1,6-anhydro sugar derivatives having a benzyloxy substituent in position 2 were not hydrolyzed at a measurable rate. ${ }^{15,24}$ The reactivity of $\mathbf{1}$ in copolymerization and solvolysis was higher than that of 5 but lower than that of 6 .

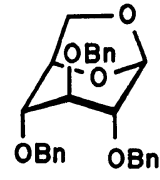

5

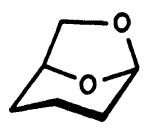

6
Structures 5 and $\mathbf{6}$

It is worthwhile to note that the polymerization of 1 could be initiated by a weak Lewis acid boron trifluoride diethyl etherate. It has been reported that $\mathrm{BF}_{3} \mathrm{OEt}_{2}$ polymerize 2-deoxygenated 1,6-anhydro-sugar derivatives $^{11,17-19}$ but are unable to polymerize 1,6-anhydro sugar derivatives having a benzyloxy substitutent on the $\mathrm{C}-2$ position. ${ }^{15}$

Table II. Copolymerization of 1,6-anhydro-3- $O$-benzyl-2,4-dideoxy- $\beta$-D-threo-hexopyranose (1) ${ }^{\mathrm{a}}$

\begin{tabular}{|c|c|c|c|c|c|c|c|c|}
\hline \multirow{2}{*}{$\begin{array}{c}\text { Exptl. } \\
\text { No. }\end{array}$} & 1 & \multicolumn{2}{|c|}{ Comonomer } & \multicolumn{2}{|c|}{ Initiator } & \multirow{2}{*}{$\frac{\text { Time }}{\min }$} & \multirow{2}{*}{$\frac{\text { Yield }}{\%}$} & \multirow{2}{*}{$X^{\mathrm{b}}$} \\
\hline & $\mathrm{mmol}$ & & $\mathrm{mmol}$ & $\mathrm{mol}^{\circ} \%$ to $\mathrm{mc}$ & nomers & & & \\
\hline $\mathrm{I}-33$ & 2.0 & 5 & 2.0 & $\mathrm{PF}_{5}$ & 5.0 & 5 & 25 & 0.98 \\
\hline $\mathrm{I}-34$ & 1.5 & 6 & 1.5 & $\mathrm{BF}_{3} \mathrm{OEt}_{2}$ & 5.0 & 100 & 8 & 0.36 \\
\hline
\end{tabular}

a Solv., dichloromethane; monomer concentration, $1.0 \mathrm{moll}^{-1}$; temp, $-60^{\circ} \mathrm{C}$.

b Mole fraction of 1 unit in the copolymer; determined by ${ }^{1} \mathrm{H}$ NMR spectroscopy. 
It has been demonstrated that, compared with other 1,6-anhydro sugar derivatives, 1 has high reactivity in terms of copolymerization, acid-catalyzed solvolysis, and initiation. It is reasonable to assume that the high reactivity of $\mathbf{1}$ is associated with the 2-deoxygenated structure which makes the reaction center less sterically hindered and more basic and nucleophilic. The importance of the inductive effect of the 2-hydroxyl group was evident from the rates of hydrolysis of methyl 2deoxy- and 3-deoxy- $\alpha$-D-glucosides relative to the parent glucoside. ${ }^{25}$

Thus, the polymerization of $\mathbf{1}$ proceeded promptly and the stereoregular polymer $\mathbf{2}$ was obtained in high yield. However, the polymer was of relatively low molecular weight and wide distribution. The stereoregularity also tended to be lowered under slightly different polymerization conditions. We assume that some side-reactions causing insertion of $\beta$ structural unit and cleavage of the polymer chain once produced are also promoted by the high reactivity of the deoxygenated structure of the monomer $\mathbf{1}$ and the polymer $\mathbf{2}$.

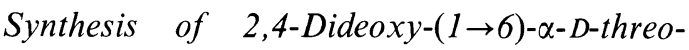 hexopyranan}

Debenzylation of the polymer 2 using sodium in liquid ammonia is summarized in Table III. When the benzene-soluble polymer was used (exptl. no. SD-1), the reaction proceeded smoothly and the debenzylation product was obtained in a quantitative yield. The other benzylated polymers were only partially soluble in the reaction medium (a mixture of toluene and 1,2-dimethoxyethane) and hence exptl. nos. ID-30 and ID-37 must be carried out in a dispersion state. After the reaction, the mixture was treated with water and dichloromethane and the product was isolated as a white powder from both the aqueous phase and the precipitate. The total yield was low owing to the insufficient contact between the reactant and reducing agent.

The debenzylated polymer SD-1 of low molecular weight was soluble in $\mathrm{Me}_{2} \mathrm{SO}$ and dimethylformamide and partially soluble in water and methanol. The polymers ID-30 and ID-37 were only partially soluble in $\mathrm{Me}_{2} \mathrm{SO}$ and dimethylformamide and insoluble in methanol. Even the polymers obtained from the aqueous phase, after once dried, became insoluble in water.

Figure 4 is the ${ }^{13} \mathrm{C}$ NMR spectrum of the polymer obtained by debenzylation of the stereoregular polymer 2 . There appeared no resonances of the benzyl group but six sharp resonances assignable to the stereoregular 2,4dideoxy- $(1 \rightarrow 6)-\alpha$-D-threo-hexopyranan (3). C1, 96.4; C-2, 38.9; C-3, 61.8; C-4, 37.0; C-5, 66.1; C-6, 68.2. Debenzylation on $\mathrm{C}-3$ position caused a large upfield shift of $9.1 \mathrm{ppm}$ for the C-3 carbon and a small downfield shift of $2.7 \mathrm{ppm}$ for each of $\mathrm{C}-2$ and $\mathrm{C}-4$ carbons. In

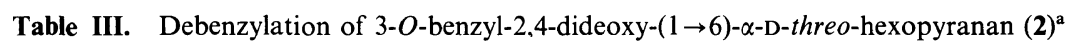

\begin{tabular}{|c|c|c|c|c|c|c|c|}
\hline \multirow{2}{*}{$\begin{array}{c}\text { Exptl. } \\
\text { No. }\end{array}$} & \multirow{2}{*}{$\begin{array}{l}2 \\
\mathrm{~g}\end{array}$} & \multirow{2}{*}{$\frac{\mathrm{Na}}{\mathrm{g}}$} & \multirow{2}{*}{$\frac{\text { Time }}{\mathrm{hr}}$} & \multicolumn{2}{|c|}{ Yield $/ \%$} & \multirow{2}{*}{$\frac{[\alpha]_{D}^{25 c}}{\operatorname{deg}}$} & \multirow{2}{*}{$\frac{[\eta]^{\mathrm{d}}}{\mathrm{dl} \mathrm{g}{ }^{-1}}$} \\
\hline & & & & Soln. & Ppt. & & \\
\hline ID-30 & 0.30 & 1.9 & 4.0 & 24 & 31 & - & - \\
\hline ID-37 & 0.28 & 0.59 & 13.7 & 37 & 15 & - & - \\
\hline SD-1 & 0.15 & 0.37 & 3.7 & 96 & 0 & +132.0 & 0.10 \\
\hline
\end{tabular}

a Solvent, a mixture of toluene $(30 \mathrm{ml})$ and 1,2-dimethoxyethane $(15 \mathrm{ml})$; liquid ammonia, $50 \mathrm{ml}$.

b After the reaction mixture was treated with water, the product was isolated from the aqueous solution and the precipitate which are given in "Soln." and "Ppt.", respectively.

c $\mathrm{Me}_{2} \mathrm{SO} ; c, 1 \mathrm{~g} / 100 \mathrm{ml}$.

d In $\mathrm{Me}_{2} \mathrm{SO}$ at $25^{\circ} \mathrm{C}$. 
K. Kobayashi et al.

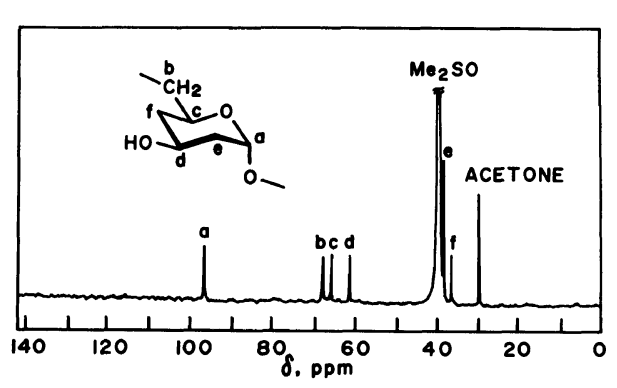

Figure 4. $50 \mathrm{MHz}{ }^{13} \mathrm{C}$ NMR spectrum of 2,4-dideoxy$(1 \rightarrow 6)-\alpha-D-t h r e o-h e x o p y r a n a n$. Solv., $\mathrm{Me}_{2} \mathrm{SO}$; concentration, $3 \%$; external lock, $\mathrm{D}_{2} \mathrm{O}$ : acetone standard (30.4 ppm). When $\mathrm{Me}_{2} \mathrm{SO}-d_{6}$ was used as the solvent, the signal $e$ was concealed behind the peak of the solvent.

addition to these signals, several weak absorptions were detected in the spectrum of the debenzylated product SD-1. Among them, the adsorption at $100.0 \mathrm{ppm}$ was assigned to the $\mathrm{C}-1$ carbon of the $\beta$-anomeric structure, and the $\beta$-anomeric content estimated from the $\alpha$ - and $\beta$-anomeric resonances was $13 \%$ which agreed with that of the benzylated polymer.

Acknowledgment. The authors are grateful to Mr. Shigeyuki Kitamura for carrying out the elemental analysis.

\section{REFERENCES}

1. C. Schuerch, Adv. Carbohydr. Chem. Biochem., 39, 157 (1981).

2. H. Sumitomo and M. Okada, "Ring-Opening Polymerization," Vol. 1, K. J. Ivin and T. Saegusa, Ed., Elsevier Applied Science, London, 1984, p 299.

3. K. Kobayashi, H. Sumitomo, and A. Yasui, Macromolecules, 12, 1019 (1979).

4. K. Kobayashi and H. Sumitomo, Macromolecules, 14, 250 (1981).
5. K. Kobayashi and H. Sumitomo, Nippon Kagaku Kaishi, 1633 (1982).

6. K. Kobayashi and H. Sumitomo, Macromolecules, 16, 710 (1983).

7. K. Kobayashi and H. Sumitomo, Polym. J., 16, 297 (1984).

8. K. Kobayashi, H. Sumitomo, and H. Ichikawa, Macromolecules, 19, 529 (1986).

9. K. Kobayashi, H. Sumitomo, and M. Takahashi, submitted to Macromolecules.

10. A. G. Kelly and J. S. Roberts, Carbohydr. Res., 77, 231 (1979).

11. K. Hatanaka, S. Kanazawa, T. Uryu, and K. Matsuzaki, J. Polym. Sci., Polym. Chem. Ed., 22, 1987 (1984).

12. M. Okada, H. Sumitomo, and Y. Hishida, Makromol. Chem., 184, 1823 (1983).

13. M. Okada, H. Sumitomo, A. Sumi, and T. Sugimoto, Macromolecules, 17, 2451 (1984).

14. M. Okada, H. Sumitomo, and A. Sumi, Carbohydr. Res., 143, 275 (1985).

15. M. Okada, H. Sumitomo, and K. Ogasawara, Polym. J., 14, 815 (1982).

16. M. Okada, H. Sumitomo, and K. Ogasawara, Polym. J., 15, 821 (1983).

17. M. Okada, H. Sumitomo, and Y. Hibino, Polym. J., 6, 256 (1974).

18. H. Komada, M. Okada, and H. Sumitomo, Macromolecules, 12, 5 (1979).

19. M. Okada, H. Sumitomo, and H. Komada, Macromolecules, 12, 395 (1979).

20. R. Jeanloz, A. M. C. Rapin, and S. Hakomori, J. Org. Chem., 26, 3939 (1961).

21. J. Godoy, S. V. Ley, and B. Lygo, J. Chem. Soc., Chem. Commun., 1381 (1984).

22. H. K. Hall, Jr., L. J. Carr, R. Kellman, and F. De Blauwe, J. Am. Chem. Soc., 96, 7265 (1974).

23. M. Okada, H. Sumitomo, M. Kanie, and H. Komada, Makromol. Chem., 181, 2315 (1980).

24. K. Kobayashi, H. Sumitomo, and H. Shiozawa, Polym. Prepr., Jpn., 33, 1299 (1984).

25. W. G. Overend, C. W. Rees, and J. S. Sequeira, J. Chem. Soc., 3429 (1962). 